\title{
The complications of awake tracheal intubation
}

\author{
J. Adam Law, MD · Ian R. Morris, MD · Andrew D. Milne, MD
}

Received: 27 April 2015/Accepted: 4 May 2015/Published online: 12 May 2015

(C) Canadian Anesthesiologists' Society 2015

We sincerely thank Dr. Benumof for his interest in our article on the incidence, success rate, and complications of awake tracheal intubation ${ }^{1}$ and particularly for his editorial commentary. ${ }^{2}$ In 1,554 awake intubations occurring over the 12 years from 2002 to 2013, we reported a year-overyear incidence of awake intubation which was surprisingly unchanged, together with a success rate of $98 \%$. We respectfully wish to clarify that the self-reported complication rate of awake intubation was $15.7 \%$, not the $2 \%$ quoted in Dr. Benumof's editorial. Indeed, as complications were self-reported in this retrospective study, the actual rate could have been even higher. Notwithstanding, as Dr. Benumof points out, it is likely that few of the 239 complications (e.g., an advancing endotracheal tube getting hung up on the larynx or encountering blood or secretions in the oropharynx) were especially clinically significant. As also emphasized by Dr.
Benumof, close attention to the effective application of airway anesthesia and the judicious use of intravenous agents may help mitigate the risk of complications and failure of awake intubation.

Conflicts of interests None declared.

\section{References}

1. Law JA, Morris IR, Brousseau PA, de la Ronde S, Milne AD. The incidence, success rate, and complications of awake tracheal intubation in 1,554 patients over 12 years: an historical cohort study. Can J Anesth 2015; DOI:10.1007/s12630-015-0387-y.

2. Benumof JL. Awake intubations are alive and well. Can J Anesth 2015; DOI:10.1007/s12630-015-0386z.
J. A. Law, MD $(\varangle)$ · I. R. Morris, MD - A. D. Milne, MD

Department of Anesthesia, Dalhousie University, QEII Health

Sciences Centre, Halifax, NS, Canada

e-mail: jlaw@dal.ca 